\title{
Effect of PI3K/Akt/mTOR signaling pathway on JNK3 in Parkinsonian rats
}

\author{
YING CHEN, XIAOZHEN ZHENG, YING WANG and JUNJIE SONG
}

\begin{abstract}
Department of Anesthesiology, The First Affiliated Hospital of Henan University, Kaifeng, Henan 475000, P.R. China
\end{abstract}
Received May 19, 2018; Accepted November 16, 2018

DOI: $10.3892 /$ etm.2018.7120

\begin{abstract}
Effect of PI3K/Akt/mTOR signaling pathway on the expression of JNK3 in Parkinsonian rats was investigated. A total of 200 rats were used for Parkinson's disease (PD) modeling and 180 models were successfully established. Rats were randomly divided into four groups including A, B, C, and D, 45 in each group. Group A was control group and no inhibitor was given. Group B was given PI3K inhibitor LY294002. Group C was given rapamycin inhibitor rapamycin; and group D was given inhibitor LY294002 and inhibitor rapamycin. JNK3 mRNA expression was detected by RT-qPCR and expression of p-mTOR protein and JNK3 protein was detected by western blot analysis. Expression level of JNK3 mRNA and protein in groups C and D was significantly lower than that in group $B(P<0.01)$. Expression level of JNK3 mRNA and protein in group D was significantly lower than that in group $\mathrm{C}(\mathrm{P}<0.01)$. Relative expression level of p-mTOR protein in groups $\mathrm{C}$ and $\mathrm{D}$ was significantly lower than that in group $\mathrm{B}(\mathrm{P}<0.01)$. Relative expression level of JNK3 protein in group $\mathrm{D}$ was significantly lower than that in group $\mathrm{C}$ $(\mathrm{P}<0.01)$. Pearson's correlation analysis showed that expression of JNK3 mRNA was positively correlated with the expression of JNK3 protein and Pearson's correlation coefficient was 0.98 $(\mathrm{P}<0.01)$. There was also a positive correlation between the expression of JNK3 mRNA and the expression of p-mTOR protein and Pearson's correlation coefficient was $0.95(\mathrm{P}<0.01)$. Expression of JNK3 protein was positively correlated with the expression of p-mTOR protein, and the Pearson's correlation coefficient was $0.93(\mathrm{P}<0.01)$. Inhibition of PI3K/Akt/mTOR signaling pathway is negatively correlated with the expression of JNK3. Inhibition of PI3K-Akt-mTOR signaling pathway leads to a decrease in the expression of JNK3, which protects dopaminergic neurons and improves PD.
\end{abstract}

Correspondence to: Dr Ying Wang, Department of Anesthesiology, The First Affiliated Hospital of Henan University, 357 Ximen Avenue, Kaifeng, Henan 475000, P.R. China

E-mail: wez4nr@163.com

Key words: PI3K/Akt/mTOR signaling pathway, Parkinson's disease, p-mTOR, JNK3, LY294002, rapamycin

\section{Introduction}

Parkinson's disease (PD) is a degenerative disease of the central nervous system that primarily affects the motor system. Early symptoms of PD include slow-motion shaking, limb stiffness, walking difficulties, and often accompanied by mental problems such as depression, anxiety and sleep disorders (1). PD occurs in middle-aged and elderly people, and its incidence is positively correlated with age, and is higher in men than in women (2). In the past 20 years, according to statistics, the incidence of PD in China has increased by nearly 20 times (3). This chronic, long-term progressive disease can only be alleviated by the present medical treatment. Late stage of PD often manifests as dementia and loss of the ability to live independently, which brings great mental impact and economic pressure to patients and their families (2). Approximately $60 \%$ of PD patients progress to severe disability after 5 years of onset, and no less than $30 \%$ of patients eventually die of PD complications, among which acne and sepsis are two most common types (4). Etiology of PD has not yet been elucidated, and it may be related to age, oxidative stress, free radicals and calcium ions and other factors. Under the combined action of genetic and environmental factors, oxidative stress, calcium overload, apoptosis and other mechanisms cause nigral striatum containing melanin neurons (mainly DA neurons) to undergo degeneration and apoptosis (5). The diagnosis of this disease is mainly based on clinical symptoms. It can be diagnosed only after neurological examinations and other diseases are excluded (6).

Phosphatidylinositol 3-kinase (PI3K) is a macromolecular protein with serine/threonine kinase activity and plays an important role in cell signal transduction (7). PI3K is activated when the cells are stimulated. Activation of PI3K promotes the conversion of PIP2 into PIP3, so as to promote recruitment of protein kinase $\mathrm{B}(\mathrm{Akt})$. After phosphorylation by protein kinase $\mathrm{K}$ (PDK), Akt directly or indirectly activates rapamycin target protein (mTOR) and mTOR is phosphorylated into p-mTOR, thereby exerting a series of biological effects such as inhibition of apoptosis and promotion of proliferation (8). $\mathrm{PI} 3 \mathrm{~K} / \mathrm{Akt} / \mathrm{mTOR}$ signaling pathway plays a protective role for nerve energy cells by participating in oxidative stress and negatively regulating apoptosis $(9,10)$. c-Jun amino-terminal kinase 3 (JNK3) is a protein that regulates programmed cell death and is mainly present in neurons in substantia nigra pars compacta. c-Jun's apoptosis-inducing function and its 
special anatomic location make it closely related to various neurodegenerative diseases such as Alzheimer's disease and PD $(11,12)$.

In the present study, effect of PI3K/Akt/mTOR pathway on the expression of JNK3 in PD mice was studied in order to further explain the pathogenesis of PD and provide a new target for the treatment of PD.

\section{Materials and methods}

Test animals. A total of 200 male Sprague-Dawley rats with a body mass of 254.7 $\pm 33.9 \mathrm{~g}$ were purchased from Shanghai SLAC Laboratory Animal Co., Ltd. (Shanghai, China) [production license SCXK (Shanghai) 2012-0002]. Rats were fed with basal diet (Shanghai SLAC Laboratory Animal Co., Ltd.) at a temperature of $21-25^{\circ} \mathrm{C}$ and a humidity of approximately $60 \%$. Rats were allowed to access water freely. The study was approved by the Ethics Committee of The First Affiliated Hospital of Henan University (Kaifeng, China).

Main reagents. Rotenone (Nanjing Xinfan Biotechnology Co., Ltd., Shanghai, China), sunflower oil (Shanghai Lisheng Chemicals Co., Ltd., Shanghai, China), LY294002 (Cell Signaling Technology, Inc., Danvers, MA, USA), rapamycin (Dalian Meilun Biotechnology Co., Ltd., Dalian, China), rabbit anti-rat JNK3/p-mTOR/ $\beta$-actin monoclonal antibody and goat anti-rabbit IgG secondary antibody (cat. nos. E-AB-60615, E-AB-63517, E-AB-30419 and E-AB-1003, respectively; Wuhan Elabscience Biotechnology Co., Ltd., Wuhan, China), TRIzol (Genenode, Beijing, China), RIPA lysate (Shanghai Huzhen Biological Technology Co., Ltd., Shanghai, China), PMSF (Nanjing Shengxing Biotechnology Co., Ltd., Nanjing, China), BCA protein kit (Shanghai Beiyi Bioequip Information Co., Ltd., Shanghai, China), reverse transcription kit and fluorescence quantitative PCR kit (both from Guangzhou Huijun Biotechnology Co., Ltd., Guangzhou, China). Primers were synthesized by Sangon Biotech Co., Ltd. (Shanghai, China).

Rat PD model construction and grouping. After two weeks of adaptive feeding, PD rat model was prepared by continuous subcutaneous injection of low dose rotenone. Rotenone was dissolved in sunflower oil to prepare an emulsion of $1.5 \mathrm{mg} / \mathrm{ml}$. Rats were weighed every morning at 9 o'clock, and emulsion was used at a dose of $1.5 \mathrm{mg} / \mathrm{kg}$. Once a day, every 7 days counts as a cycle. Injection was discontinued for a day after each cycle and a total of 3 cycles were performed. After the completion of screening, model animals were grouped. Criteria for successful modeling (13): Occasional paralysis of limbs, inconvenience of walking, inability to eat, gradual loss of ability to resist arrest, yellowing of hair and bow back. Two rats died after 3 cycles, 18 failed to meet PD modeling criteria, and finally 180 rats were modeled successfully. The 180 rats were randomly divided into 4 groups including $\mathrm{A}, \mathrm{B}$, $\mathrm{C}$ and D, with 45 in each group. Group A was control group and was given physiological saline. Group B was LY294002 group, LY294002 as PI3K inhibitor was used at a concentration of $10 \mathrm{mmol} / \mathrm{l}$, and the lateral ventricle was injected at a dose of $10 \mu \mathrm{l} / \mathrm{kg}$ according to the weight of each rat. Group C was rapamycin (a specific inhibitor of mTOR protein) group and rapamycin $(0.32 \mathrm{ng}$ in $4 \mu \mathrm{l})$ was injected into the lateral ventricle. Group D was LY294002 combined with rapamycin group, and the dose and injection method were the same as above.

Detection of JNK3 expression by RT-qPCR. TRIzol extraction of total RNA from rat substantia nigra tissue $(100 \mathrm{mg})$ was performed according to the instructions of the kit. A total of $20 \mu 1$ reaction system was prepared and cDNA was synthesized according to the following conditions: $37^{\circ} \mathrm{C}$ for $15 \mathrm{~min}$ and $85^{\circ} \mathrm{C}$ for $5 \mathrm{sec}$. A total of $2 \mu \mathrm{l}$ of reverse transcription product was used for the PCR reaction according to the instructions of TaqMan qPCR kit (Thermo fisher, Waltham, MA, USA) and GAPDH was used as endogenous control. Reaction conditions were: $95^{\circ} \mathrm{C}$ for $60 \mathrm{sec}$, followed by 40 cycles of $95^{\circ} \mathrm{C}$ for $10 \mathrm{sec}$ and $60^{\circ} \mathrm{C}$ for $30 \mathrm{sec}$. This experiment was performed in triplicate manner and data were processed using $2^{-\Delta \mathrm{Cq}}$ method (14). Primer sequences are listed in Table I.

Western blot analysis. Protein lysate was prepared using $10 \mathrm{ml}$ of RIPA and $100 \mu \mathrm{l}$ of PMS protease inhibitor to extract total protein form $100 \mathrm{mg}$ rat substantia nigra tissue. BCA method was used to measure protein concentration. A total of $50 \mu \mathrm{l}$ of protein was mixed with $200 \mu \mathrm{l}$ of $5 \mathrm{X}$ loading buffer and subjected to SDS-PAGE electrophoresis. After that, gel transfer was performed at $4 \mathrm{~mA} / \mathrm{cm}^{2}$ for $1 \mathrm{~h}$. Blocking with $5 \%$ BSA was performed for $1 \mathrm{~h}$, followed by incubation with JNK3 monoclonal antibody (1:1,000), p-mTOR monoclonal antibody $(1: 1,000)$ and $\beta$-actin monoclonal antibody $(1: 5,000)$ for $16 \mathrm{~h}$ at $4^{\circ} \mathrm{C}$. After washing with PBS 3 times, membrans were washed 3 times with PBS, followed by incubation with goat anti-IgG secondary antibody $(1: 5,000)$ at room temperature for $1 \mathrm{~h}$. ECL luminescence reagent was added to develop signals and Quantity One software (Bio Rad, Hercules, CA, USA) was used to scan membranes. Relative expression level of the JNK3/p-mTOR protein (grayscale) of JNK3/p-mTOR grayscale of $\beta$-actin.

Statistical analysis. SPSS 19.0 statistical package (IBM Corp., Armonk, NY, USA) was used for all analyses. Results were expressed as mean \pm standard deviation (SD), and were analyzed using non-parametric K-S test according to data distribution characteristics. Relationship between JNK3 and p-mTOR protein expression was analyzed using Pearson's correlation, and the significance level was $\alpha=0.05$.

\section{Results}

Detection of JNK3 mRNA expression by RT-qPCR. Expression level of JNK3 mRNA in experimental group B, C and D was $0.79 \pm 0.03,0.50 \pm 0.01$ and $0.17 \pm 0.01$, respectively, which was significantly lower than that in control group A $(1.00 \pm 0.05$; $\mathrm{P}<0.01)$. Expression of JNK3 mRNA in group C and D was significantly lower than that in group $\mathrm{B}(\mathrm{P}<0.01)$, and expression level of JNK3 mRNA in group D was significantly lower than that in group $\mathrm{C}(\mathrm{P}<0.01)$ (Fig. 1).

Western blot analysis of JNK3 protein. Relative expression level of JNK3 protein in experimental groups B, C and D was $0.53 \pm 0.14,0.45 \pm 0.09$ and $0.15 \pm 0.08$, respectively, which was significantly lower than that in control group $(0.73 \pm 0.05$; 
Table I. Primer sequences.

\begin{tabular}{llc}
\hline Items & \multicolumn{1}{c}{ Forward } & \multicolumn{1}{c}{ Reverse } \\
\hline GAPDH & 5'-TGGTCTACATGTTCCAGTATGACT-3' & 5'-CCATTTGATGTTAGCGGGATCTC-3' \\
JNK3 & 5'-CCACGCAGATCAAACAGGA-3' & 5'-CCACGCAGATCAAACAGGA-3'
\end{tabular}

JNK3, c-Jun amino-terminal kinase 3.

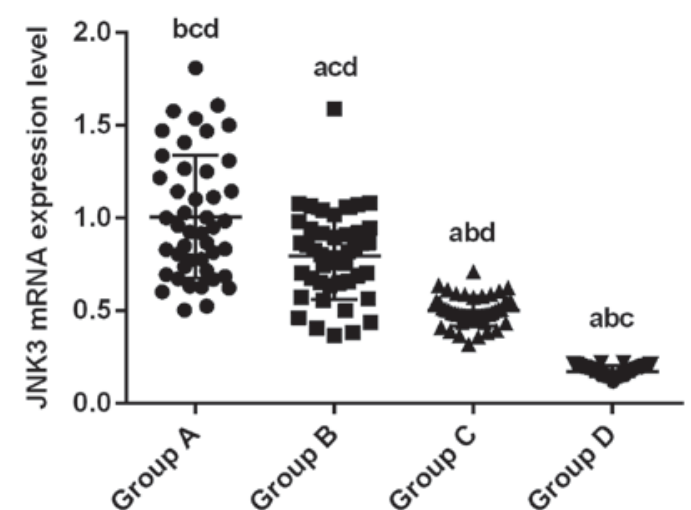

Figure 1. Detection of JNK3 mRNA expression by RT-qPCR. Normalized expression level of JNK3 mRNA in experimental group B, C and D was $0.79 \pm 0.03,0.50 \pm 0.01$ and $0.17 \pm 0.01$, respectively, which was significantly lower than that in control group A $(1.00 \pm 0.05 ; \mathrm{P}<0.01)$. Expression of JNK3 mRNA in group C and D was significantly lower than that in group $\mathrm{B}(\mathrm{P}<0.01)$, and expression level of JNK3 mRNA in group D was significantly lower than that in group $\mathrm{C}(\mathrm{P}<0.01) .{ }^{\mathrm{a}} \mathrm{P}<0.01$, compared with group $\mathrm{A}$. ${ }^{\mathrm{b}} \mathrm{P}<0.01$, compared with group $\mathrm{B}$. ${ }^{\mathrm{c}} \mathrm{P}<0.01$, compared with group $\mathrm{C}$. ${ }^{\mathrm{d}} \mathrm{P}<0.01$, compared with group D. JNK3, c-Jun amino-terminal kinase 3.

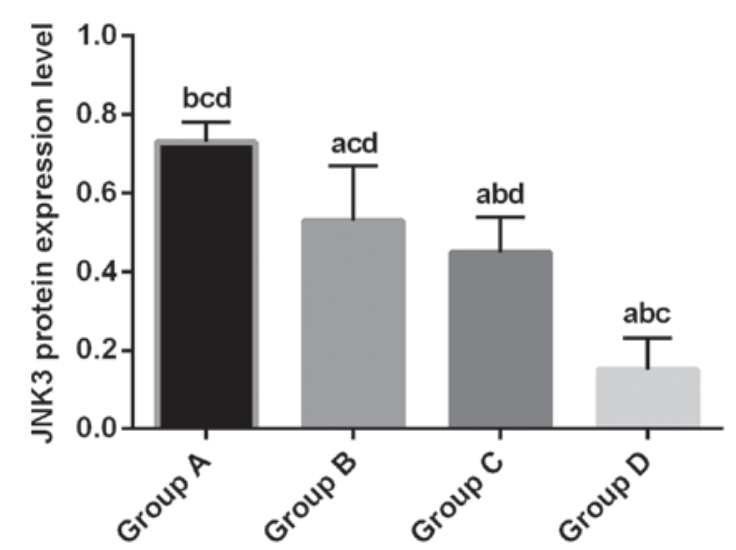

Figure 2. JNK3 protein expression detected by western blot analysis. Normalized expression level of JNK3 protein in experimental groups B, $\mathrm{C}$ and $\mathrm{D}$ was $0.53 \pm 0.14,0.45 \pm 0.09$ and $0.15 \pm 0.08$, respectively, which was significantly lower than that in control group $(0.73 \pm 0.05 ; \mathrm{P}<0.05)$. Relative expression level of JNK3 protein in group $\mathrm{C}$ and $\mathrm{D}$ was significantly lower than that in group $\mathrm{B}(\mathrm{P}<0.01)$. Relative expression level of JNK3 protein in group $\mathrm{D}$ was significantly lower than that in group $\mathrm{C}(\mathrm{P}<0.01)$. ${ }^{\mathrm{a}} \mathrm{P}<0.01$, compared with group $\mathrm{A} .{ }^{\mathrm{b}} \mathrm{P}<0.01$, compared with group $\mathrm{B}$. ${ }^{\mathrm{C}} \mathrm{P}<0.01$, compared with group C. ${ }^{\mathrm{d}} \mathrm{P}<0.01$, compared with group D. JNK3, c-Jun amino-terminal kinase 3 .

$\mathrm{P}<0.05)$. Relative expression level of JNK3 protein in group C and $\mathrm{D}$ was significantly lower than that in group $\mathrm{B}(\mathrm{P}<0.01)$. Relative expression level of JNK3 protein in group D was significantly lower than that in group $\mathrm{C}(\mathrm{P}<0.01)$ (Fig. 2).

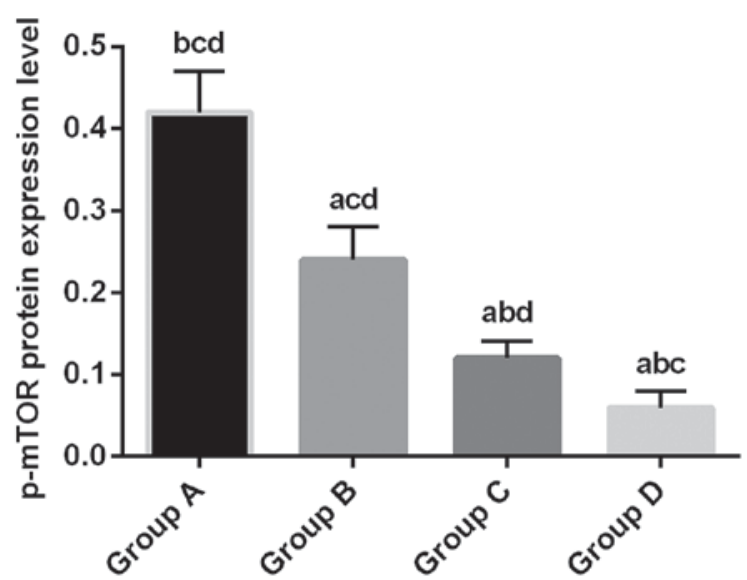

Figure 3. Detection of p-mTOR protein expression by western blot analysis. Normalized expression level of p-mTOR protein in the experimental group B, $\mathrm{C}$ and $\mathrm{D}$ was $0.24 \pm 0.04,0.12 \pm 0.02$ and $0.06 \pm 0.02$, respectively, which was significantly lower than that in control group A $(0.42 \pm 0.05 ; \mathrm{P}<0.05)$. Relative expression level of $\mathrm{p}$-mTOR protein in group $\mathrm{C}$ and $\mathrm{D}$ was significantly lower than that in group $\mathrm{B}(\mathrm{P}<0.01)$. Relative expression level of JNK3 protein in group D was significantly lower than that in group $\mathrm{C}(\mathrm{P}<0.01)$. ${ }^{\mathrm{P}} \mathrm{P}<0.01$, compared with group $\mathrm{A} .{ }^{\mathrm{b}} \mathrm{P}<0.01$, compared with group $\mathrm{B} .{ }^{\mathrm{c}} \mathrm{P}<0.01$, compared with group $\mathrm{C} .{ }^{\mathrm{d}} \mathrm{P}<0.01$, compared with group $\mathrm{D}$. mTOR, rapamycin target protein.

Table II. Correlation analysis of JNK3 and p-mTOR protein expression.

\begin{tabular}{lrcc}
\hline $\begin{array}{l}\text { Pearson 's correlation } \\
\text { coefficient }\end{array}$ & $\begin{array}{r}\text { JNK3 } \\
\text { mRNA }\end{array}$ & $\begin{array}{r}\text { JNK3 } \\
\text { protein }\end{array}$ & $\begin{array}{c}\text { p-mTOR } \\
\text { protein }\end{array}$ \\
\hline JNK3 mRNA & 1 & $/$ & $/$ \\
JNK3 protein & 0.98 & 1 & $/$ \\
p-mTOR protein & 0.95 & 0.93 & 1 \\
\hline
\end{tabular}

JNK3, c-Jun amino-terminal kinase 3; mTOR, rapamycin target protein.

Western blot analysis of p-mTOR protein expression. Relative expression level of p-mTOR protein in the experimental group B, C and D was $0.24 \pm 0.04,0.12 \pm 0.02$ and $0.06 \pm 0.02$, respectively, which was significantly lower than that in control group A $(0.42 \pm 0.05 ; \mathrm{P}<0.05)$. Relative expression level of $\mathrm{p}$-mTOR protein in group $\mathrm{C}$ and $\mathrm{D}$ was significantly lower than that in group $\mathrm{B}(\mathrm{P}<0.01)$. Relative expression level of JNK3 protein in group $D$ was significantly lower than that in group $\mathrm{C}(\mathrm{P}<0.01)$ (Fig. 3$)$. 
Correlation analysis of JNK3 and p-mTOR protein expression. Pearson's correlation analysis showed that expression of JNK3 mRNA was positively correlated with JNK3 protein expression and Pearson's correlation coefficient was $0.98(\mathrm{P}<0.01)$. There was also a positive correlation between the expression of JNK3 mRNA and the expression of p-mTOR protein and Pearson's correlation coefficient was $0.95(\mathrm{P}<0.01)$. Besides, expression of JNK3 protein was positively correlated with the expression of $\mathrm{p}$-mTOR protein, and the Pearson's correlation coefficient was $0.93(\mathrm{P}<0.01)$ (Table II).

\section{Discussion}

PD is the most common disabling disease in middle-aged and elderly people. Its main pathological feature is degeneration and necrosis of DA neurons in the nigrostriatal (15). PI3K/AKT/mTOR signaling pathway plays an important regulatory role in many life activities such as cell metabolism, cell growth, biosynthesis, as well as development of cancer, degenerative diseases, and diabetes $(16,17)$. JNK3 is one of the major MAPK family members in the brain. It is reported that calcium overload and oxygen free radicals can activate JNK3, thereby inducing the expression of apoptotic proteins such as p53 and FasL and inducing the expression of caspases, so as to accelerate the process of cell apoptosis (3). Therefore, this study aimed to investigate the effect of PI3K/Akt/mTOR signaling pathway on the expression of JNK3 in PD mice, so as to further explain the pathogenesis of PD and provide a new target for the treatment of PD.

LY294002 is a specific inhibitor of PI3K, and rapamycin is a specific inhibitor of mTOR. Both of them can inhibit $\mathrm{PI} 3 \mathrm{~K} / \mathrm{Akt} / \mathrm{mTOR}$ signaling pathway. In this study, the relative expression levels of JNK3 mRNA and JNK3 protein were decreased when LY294002 and rapamycin were administered, and the combination of the two inhibitors resulted in the lowest expression level, indicating that both PI3K inhibitor and rapamycin inhibitor can inhibit the expression of JNK3, and the inhibitory effect is enhanced when they are used together. At the same time, the relative expression level of p-mTOR protein was also decreased after inhibiting PI3K and/or mTOR, indicating that mTOR indeed participates in the PI3K/Akt/ mTOR signaling pathway. Heras-Sandoval et al (18) also found that PI3K/AKT pathway can regulate mTOR activity in Alzheimer's disease and PD, and this signaling pathway can protect neuronal cells by regulating autophagy. This regulatory effect has also been reported by Singh et al (19). Correlation analysis showed that JNK3 mRNA expression was positively correlated with JNK3 protein expression, which was in line with the central law. There was a positive correlation between the expression of JNK3 mRNA and the expression of p-mTOR protein. The positive correlation between the expression of JNK3 protein and expression of p-mTOR protein indicates that the inhibition of PI3K/Akt/mTOR signaling pathway can downregulate the expression of JNK3. Expression of JNK3 decreased with inhibition degree of PI3K-Akt-mTOR signaling pathway. Expression level of JNK3 mRNA in group C was always lower than that in group B, indicating that the inhibitory effect of LY294002 was better than that of rapamycin. This may be because mTOR is a downstream effector gene of PI3K. Although mTOR was inhibited in group C but PI3K was not inhibited, PI3K may exert its inhibitory action through other pathways. Therefore, JNK3, PI3K, Akt, and mTOR are all expected to become therapeutic targets for PD.

One of the advantages of this study is that the PD rat model prepared by the rotenone method is similar to the natural progression of human PD. Rotenone can poison cells by inhibiting nerve cell respiration and disrupting the chain of oxidative phosphorylation (20). Betarbet et al (21) was the first to successfully establish rotenone-induced PD model. This model has been studied and shows a high degree of consistency with humans in behavioral changes and pathological features. In contrast to mice, we chose rats for model construction. Due to its larger brain volume, it is more conducive to the nigrostriatal localization and the extraction of substantia nigra tissue. Regarding drug administration, continuous injection of low doses not only reduces the death of rats, but also mimics the chronic progression of PD.

Our study also has some limitations. Pathogenesis of PD is still unclear and it is hard to mimic the damage of other brain regions outside the substantia nigra (22). Although JNK3 mRNA expression was positively correlated with JNK3 protein expression, JNK3 mRNA expression was positively correlated with p-mTOR protein expression and JNK3 protein expression was positively correlated with p-mTOR protein expression, Pearson's coefficient alone cannot explain the causal relationship between them. Although numerous studies $(23,24)$ have demonstrated that mTOR is a downstream target of Akt, the PI3K/Akt/mTOR signaling pathway is one of the most widely studied signaling pathways involved in cell growth and apoptosis. Raha et al (25) also found that activation of MAPK family can inhibit $\mathrm{PI} 3 \mathrm{~K} / \mathrm{Akt} / \mathrm{mTOR}$ signaling pathway by inducing autophagy, and JNK3 is also a member of MAPK family, so JNK3 may also act on mTOR. However, whether this interaction is direct or indirect is unknown. In this study, inhibition of PI3K/Akt $/ \mathrm{mTOR}$ signaling pathway indeed downregulated JNK3 expression.

In conclusion, inhibition of the PI3K/Akt/mTOR signaling pathway leads to a decrease in expression level of JNK3. Expression level of JNK3 decreases with increase in degree of inhibition of PI3K-Akt-mTOR signaling pathway, thereby protecting dopaminergic neurons and improving PD.

\section{Acknowledgements}

Not applicable.

\section{Funding}

This study was supported by the project of 'Effects of ketamine on the pathological process and cognitive function of synuclein in Parkinson's disease (project approval no. 81600940).

\section{Availability of data and materials}

The datasets used and/or analyzed during the present study are available from the corresponding author on reasonable request.

\section{Authors' contributions}

YC conceived and designed this study. XZ and YW were responsible for rat PD model construction and grouping. YC 
and JS performed PCR and western blot analysis. All authors read and approved the final manuscript.

\section{Ethics approval and consent to participate}

The study was approved by the Ethics Committee of The First Affiliated Hospital of Henan University (Kaifeng, China).

\section{Patient consent for publication}

Not applicable.

\section{Competing interests}

The authors declare that they have no competing interests.

\section{References}

1. Khwanraj K, Madlah S, Grataitong $\mathrm{K}$ and Dharmasaroja $\mathrm{P}$ Comparative mRNA expression of eEF1A isoforms and a $\mathrm{PI} 3 \mathrm{~K} / \mathrm{Akt} / \mathrm{mTOR}$ pathway in a cellular model of Parkinson's disease. Parkinsons Dis 2016: 8716016, 2016.

2. Chong ZZ, Shang YC, Wang S and Maiese K: A critical kinase cascade in neurological disorders: PI 3-K, Akt, and mTOR. Future Neurol 7: 733-748, 2012.

3. Pei B, Yang M, Qi X, Shen X, Chen X and Zhang F: Quercetin ameliorates ischemia/reperfusion-induced cognitive deficits by inhibiting ASK1/JNK3/caspase-3 by enhancing the Akt signaling pathway. Biochem Biophys Res Commun 478: 199-205, 2016

4. Chan CS, Guzman JN, Ilijic E, Mercer JN, Rick C, Tkatch T, Meredith GE and Surmeier DJ: 'Rejuvenation' protects neurons in mouse models of Parkinson's disease. Nature 447: 1081-1086, 2007.

5. Thevathasan W, Coyne TJ, Hyam JA, Kerr G, Jenkinson N, Aziz TZ and Silburn PA: Pedunculopontine nucleus stimulation improves gait freezing in Parkinson disease. Neurosurgery 69: 1248-1253, discussion 1254, 2011.

6. Dewey DC, Miocinovic S, Bernstein I, Khemani P, Dewey RB III, Querry R, Chitnis S and Dewey RB Jr: Automated gait and balance parameters diagnose and correlate with severity in Parkinson disease. J Neurol Sci 345: 131-138, 2014.

7. Zhang L, Wang H, Xu J, Zhu J and Ding K: Inhibition of cathepsin $\mathrm{S}$ induces autophagy and apoptosis in human glioblastoma cell lines through ROS-mediated PI3K/AKT/mTOR/p70S6K and JNK signaling pathways. Toxicol Lett 228: 248-259, 2014.

8. Heavey S, O'Byrne KJ and Gately K: Strategies for co-targeting the PI3K/AKT/mTOR pathway in NSCLC. Cancer Treat Rev 40: 445-456, 2014.

9. Manfredi GI, Dicitore A, Gaudenzi G, Caraglia M, Persani L and Vitale G: PI3K/Akt/mTOR signaling in medullary thyroid cancer: A promising molecular target for cancer therapy. Endocrine 48: 363-370, 2015

10. Asati V, Mahapatra DK and Bharti SK: PI3K/Akt/mTOR and Ras/Raf/MEK/ERK signaling pathways inhibitors as anticancer agents: Structural and pharmacological perspectives. Eur J Med Chem 109: 314-341, 2016.

11. Yeh YH, Wang SW, Yeh YC, Hsiao HF and Li TK: Rhapontigenin inhibits TGF- $\beta$-mediated epithelial mesenchymal transition via the PI3K/AKT/mTOR pathway and is not associated with HIF-1 $\alpha$ degradation. Oncol Rep 35: 2887-2895, 2016.
12. Wen XR, Fu YY, Liu HZ, Wu J, Shao XP, Zhang XB, Tang M, Shi Y, Ma K, Zhang F, et al: Neuroprotection of sevoflurane against ischemia/reperfusion-induced brain injury through inhibiting JNK3/caspase-3 by enhancing Akt signaling pathway. Mol Neurobiol 53: 1661-1671, 2016.

13. von Wrangel C, Schwabe K, John N, Krauss JK and Alam M: The rotenone-induced rat model of Parkinson's disease: Behavioral and electrophysiological findings. Behav Brain Res 279: 52-61, 2015.

14. Livak KJ and Schmittgen TD: Analysis of relative gene expression data using real time quantitative PCR and the 2(Delta Delta C(T)) method. Methods 25: 402 408, 2001.

15. Granato M, Rizzello C, Gilardini Montani MS, Cuomo L, Vitillo M, Santarelli R, Gonnella R, D'Orazi G, Faggioni A and Cirone M: Quercetin induces apoptosis and autophagy in primary effusion lymphoma cells by inhibiting PI3K/AKT/mTOR and STAT3 signaling pathways. J Nutr Biochem 41: 124-136, 2017.

16. Hou X, Zhao M, Wang T and Zhang G: Upregulation of estrogen receptor mediates migration, invasion and proliferation of endometrial carcinoma cells by regulating the PI3K/AKT/mTOR pathway. Oncol Rep 31: 1175-1182, 2014.

17. Mabuchi S, Kuroda H, Takahashi $\mathrm{R}$ and Sasano T: The $\mathrm{PI} 3 \mathrm{~K} / \mathrm{AKT} / \mathrm{mTOR}$ pathway as a therapeutic target in ovarian cancer. Gynecol Oncol 137: 173-179, 2015.

18. Heras-Sandoval D, Pérez-Rojas JM, Hernández-Damián J and Pedraza-Chaverri J: The role of PI3K/AKT/mTOR pathway in the modulation of autophagy and the clearance of protein aggregates in neurodegeneration. Cell Signal 26: 2694-2701, 2014.

19. Singh AK, Kashyap MP, Tripathi VK, Singh S, Garg G and Rizvi SI: Neuroprotection through rapamycin-induced activation of autophagy and PI3K/Akt1/mTOR/CREB signaling against amyloid- $\beta$-induced oxidative stress, synaptic/neurotransmission dysfunction, and neurodegeneration in adult rats. Mol Neurobiol 54: 5815-5828, 2017.

20. Ablat N, Lv D, Ren R, Xiaokaiti Y, Ma X, Zhao X, Sun Y, Lei H, Xu J, Ma Y, et al: Neuroprotective effects of a standardized flavonoid extract from safflower against a rotenone-induced rat model of Parkinson's disease. Molecules 21: 1107, 2016.

21. Betarbet R, Sherer TB, MacKenzie G, Garcia-Osuna M, Panov AV and Greenamyre JT: Chronic systemic pesticide exposure reproduces features of Parkinson's disease. Nat Neurosci 3: 1301-1306, 2000.

22. Xiong ZK, Lang J, Xu G, Li HY, Zhang Y, Wang L, Su Y and Sun AJ: Excessive levels of nitric oxide in rat model of Parkinson's disease induced by rotenone. Exp Ther Med 9: 553-558, 2015.

23. Zhang Y, Kwok-Shing Ng P, Kucherlapati M, Chen F, Liu Y, Tsang YH, de Velasco G, Jeong KJ, Akbani R, Hadjipanayis A, et al: A pan-cancer proteogenomic atlas of PI3K/AKT/mTOR pathway alterations. Cancer Cell 31: 820-832.e3, 2017.

24. Baek SH, Ko JH, Lee JH, Kim C, Lee H, Nam D, Lee J, Lee SG, Yang WM, Um JY, et al: Ginkgolic acid inhibits invasion and migration and TGF- $\beta$-induced EMT of lung cancer cells through PI3K/Akt/mTOR inactivation. J Cell Physiol 232: 346-354, 2017.

25. Raha S, Yumnam S, Hong GE, Lee HJ, Saralamma VV, Park HS, Heo JD, Lee SJ, Kim EH, Kim JA, et al: Naringin induces autophagy-mediated growth inhibition by downregulating the $\mathrm{PI} 3 \mathrm{~K} / \mathrm{Akt} / \mathrm{mTOR}$ cascade via activation of MAPK pathways in AGS cancer cells. Int J Oncol 47: 1061-1069, 2015. 